Electronic Supporting Information

\title{
Oxygen redox reaction in Ionic Liquid and Ionic Liquid-like based electrolytes: a scanning electrochemical microscopy study
}

Irene Ruggeri, Catia Arbizzani, Stefania Rapino*, Francesca Soavi ${ }^{*}$

Department of Chemistry Giacomo Ciamician - Alma Mater Studiorum Bologna University

*stefania.rapino3@unibo.it; *francesca.soavi@unibo.it
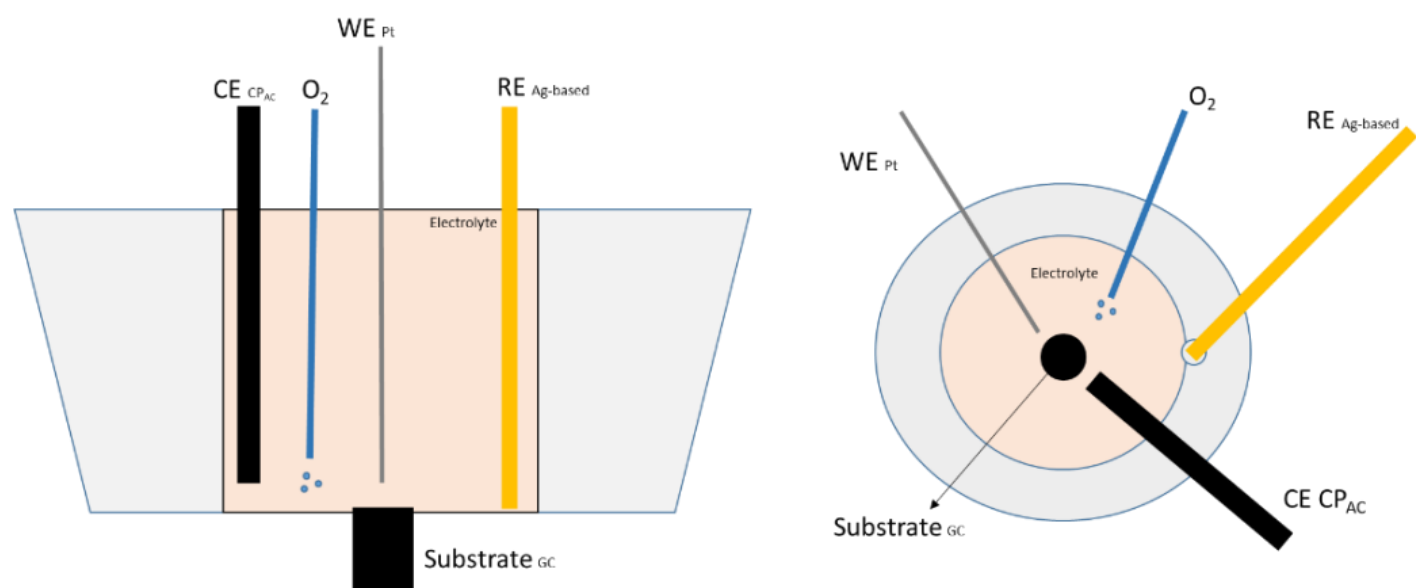

Figure S1. Scheme of the cell used in SECM. 